\title{
Pedostructure Concept: A New Paradigm for Quantifying Soil Structural Characteristics
}

\author{
Aliku $\mathbf{0}^{1 *}$ and Ikoko $\mathrm{CB}^{2}$ \\ ${ }^{1}$ Department of Agronomy, University of Ibadan, Nigeria \\ ${ }^{2}$ University of Nigeria, Nigeria \\ *Corresponding author: Aliku O, Department of Agronomy, University of Ibadan, Faculty of Agriculture, Nigeria
}

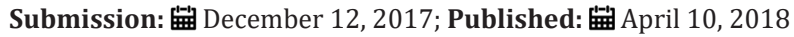

\begin{abstract}
Characterization of the internal organization of the soil can aid the quantification of soil structural characteristics, and also enhance the understanding of the soil processes for adequate agricultural and environmental soil management. However, the current soil physics approach describes soil structure and its hydraulic properties independent from the internal organization and hydro-structural functioning of the soil medium. The pedostructure concept is a new paradigm in soil structural analysis that is aimed at understanding the hydrostructural characterization, behaviour, configuration, and interactions of the soil-water medium, by taking into account the internal organization and functionality, with respect to water flow, of the soil.

The pedostructure concept adopts a conceptual and functional model in which shrinkage and swelling curves are used to characterize the hydrostructural equilibrium and kinetics of soil-water medium, respectively. The shrinkage curve represents and characterizes the equilibrium state of the soil water medium, while the swelling curve represents the dynamics of the medium as it returns to equilibrium due to abrupt changes in moisture conditions. This is important in understanding the dynamics of water flow, and the fate of fertilizers and pollutants in the soil. Thus, this could enhance proper management of soil for improved agricultural production and enhanced environmental quality.
\end{abstract}

Keywords: Hydrostructural characterization; Pedostructure; Shrinkage curve; Swelling curve; Soil internal organization

\section{Introduction}

Soil structure is an important soil property that influences most soil processes. It is often affected by farm operations such as tillage, seedbed preparation, mulching etc., which are usually carried out to enhance air, water, and nutrient mobility, with the aim of creating favorable conditions for crop growth and yield production. Hence, the behaviour of a soil as a composite body depends on its structure, which describes the manner in which the various particles are packed and held together to form a continuous spatial network that constitutes the soil matrix or the soil fabric $[1,2]$.

Defined soil structure as the arrangement and organization of the particles in the soil, making reference to it as the internal configuration of the soil matrix. He explained further that, since soil particles differ in shape, size, and orientation, and can be variously associated and interlinked, their mass can form complex and irregular patterns that are difficult to characterize in exact geometric terms. Also, the inherently unstable nature of soil structure and its non-uniformity in space due to the effects of changes in climate, biological activities, soil management practices, and its vulnerability to mechanical and physico-chemical practices makes it complicated [2].
Although, there are no truly universally applicable ways to measure soil structure, several methods are being used to characterize soil structure by measuring certain soil parameters that depend on structure $[2,3]$. Noted that these soil parameters (bulk density, total porosity, penetration resistance etc.) correlate well with soil structure, and as such, they are used as indices of soil structure. These methods describe soil properties independently from their aggregated organization and hydro-structural dynamics [4]. Thus, in understanding soil structure, soil hydrological properties and the dynamics of soil processes for soil structure characterization and effective soil management for sustainable crop production, it is not sufficient to study the properties of individual soil particles [2].

Hence, a new functional model of soil-water medium organization, where swelling aggregates of a hierarchy of sizes, constitute the internal structure of a soil horizon, has been presented [5]. Figure 1 is an illustration of the internal organization of a pedon, hierarchized into its hydro-functional levels of organization [6]. The understanding of this representation has led to the definition of a new paradigm (pedostructure) for soil- 
water interaction modeling, soil hydro-structural properties and parameter characterization [7].

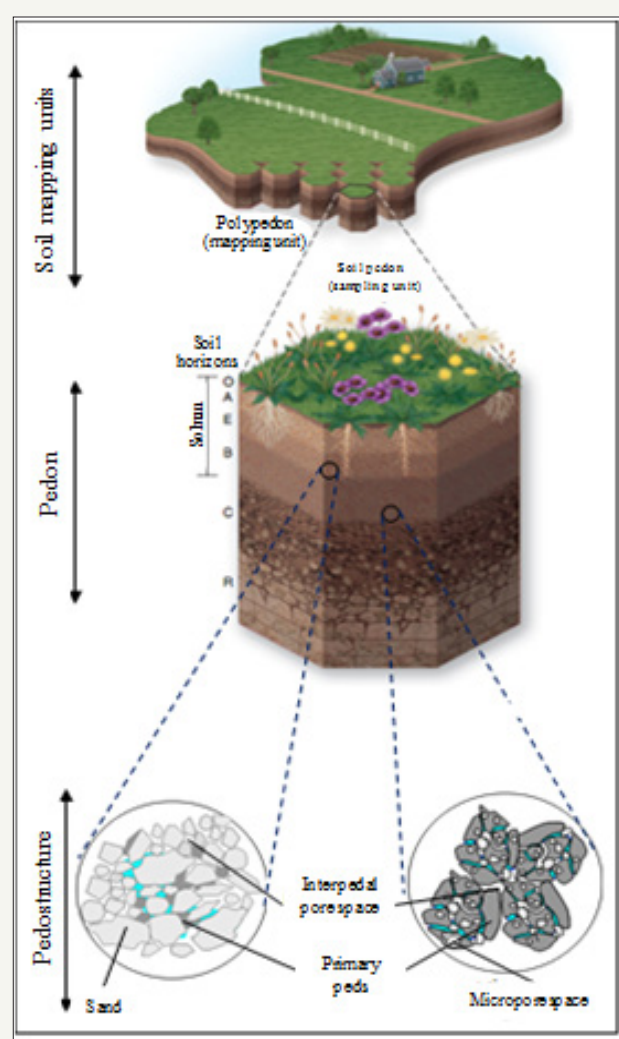

Figure 1: A representation of the internal organization of pedon, hierarchized into its hydro-functional levels of organization.

\section{The Pedostructure Concept}

The word pedostructure refers to the soil medium organization as an assembly of primary peds that conditions soil processes. It is a representative volume of the soil medium structure in the soil horizons [8]. The pedostructure concept is a new paradigm of soil characterization that defines soil behaviour based on its structure [9]. They explained that this concept characterizes a soil based upon soil structural properties to predict soil-water behaviour. This is because the current soil retention data has insufficient information regarding soil structure and the continuity of pores, which are important determinants of conductivity and other soil hydraulic properties [10].

[8] Stated that the pedostructure concept permits the physical definition of the variables and parameters describing the soil structure (arrangement of soil particles) and the soil organization (water and air repartition relative to the solid surfaces of the structure). According to [11], there are fifteen (15) unique pedostructure parameters inherent to every soil, to describe the pedostructure (Table 1). Mohtar RH [4] further explained that, under the pedostructure concept, the soil medium organization is represented by two nested Representative Structural Volumes (RSVs)-a RSV of the soil horizon and that of the soil fabric, namely, the pedostructure. They also highlighted two functions (the shrinkage curve and the swelling curve) of the soil fabric for characterizing these functional RSVs and their dynamics, while the characterization and parameterization of the hydro-structural functions of the pedostructure are obtained using the following relations described by [4] and [9].

Table 1: Pedostructure parameters and their definitions.

\begin{tabular}{|c|c|c|c|}
\hline Parameter & Unit & Curve for Extraction & Definition \\
\hline $\mathrm{V}_{\mathrm{o}}$ & $\mathrm{dm}^{3} \mathrm{k}_{\mathrm{gsoil}}^{-1}$ & Shrinkage & Specific volume at non-swelling micropores (oven-dry) state \\
\hline $\mathrm{W}_{\mathrm{L}}$ & $\mathrm{kg}_{\text {water }} \mathrm{k}_{\mathrm{gsoil}}{ }^{-1}$ & Shrinkage & Specific water content at saturation \\
\hline $\mathrm{W}_{\mathrm{N}}$ & $\mathrm{kg}_{\text {water }} \mathrm{kg}_{\text {soil }}{ }^{-1}$ & Shrinkage & Specific water content at non-swelling micropores water level \\
\hline $\mathrm{W}_{\mathrm{M}}$ & $\mathrm{kg}_{\text {water }} \mathrm{kg}_{\text {soil }}{ }^{-1}$ & Shrinkage & Specific water content at change of drying from macropores to micropores \\
\hline $\mathrm{K}_{\mathrm{N}}$ & $\mathrm{kg}_{\text {soil }} \mathrm{kg}_{\text {water }}-1$ & Shrinkage & $\begin{array}{l}\text { Constant of equilibrium (slope of shrinkage curve) between } \mathrm{W}_{\mathrm{bs}} \text { (swelling micro pore water } \\
\text { pool) and } \mathrm{W}_{\mathrm{re}} \text { (non-swelling micro pore water pool) during drying }\end{array}$ \\
\hline км & $\mathrm{kg}_{\text {soil }} \mathrm{kg}_{\text {water }}{ }^{-1}$ & Shrinkage & $\begin{array}{l}\text { Constant of equilibrium (slope of shrinkage curve) between } \mathrm{W}_{\mathrm{bs}} \text { (swelling micro pore water } \\
\text { pool) and } \mathrm{W}_{\mathrm{st}} \text { (non-swelling macro pore water pool) during drying }\end{array}$ \\
\hline $\mathrm{K}_{\mathrm{bs}}$ & $\mathrm{kg}_{\text {soil }} \mathrm{dm}_{\text {soil. }}{ }^{3}$ & Shrinkage & Scaling ratio between the pedostructure and primary peds \\
\hline $\mathrm{Em}_{\mathrm{a}}$ & $\mathrm{j} \mathrm{kgsoil}^{-1}$ & Potential & Potential energy of the external surface of primary peds \\
\hline $\mathrm{E}_{\mathrm{mi}}$ & $\mathrm{j} \mathrm{kg}_{\text {soil }}{ }^{-1}$ & Swelling & Potential energy of the internal surfaces of primary peds \\
\hline${ }^{\alpha} \mathrm{L}$ & $\mathrm{kg}_{\text {soil }} \mathrm{kg}_{\text {water }}{ }^{-1}$ & Conductivity & $\begin{array}{c}\text { Constant of the exponential increase of macro pore hydraulic conductivity with macro pore } \\
\text { water content at saturation }\end{array}$ \\
\hline$\alpha^{\circ}$ & $\mathrm{kg}_{\text {soil }} \mathrm{kg}_{\text {water }}-1$ & Conductivity & $\begin{array}{l}\text { Constant of the exponential increase of macro pore hydraulic conductivity with macro pore } \\
\text { water content at the dry point of macro porosity }\end{array}$ \\
\hline $\mathrm{K}_{\mathrm{ma}}$ & $\mathrm{dms}^{-1}$ & Conductivity & Hydraulic conductivity at the dry point of macroporosity \\
\hline $\mathrm{K}_{\text {sat }}$ & $\mathrm{dms}^{-1}$ & Conductivity & Hydraulic conductivity at saturation \\
\hline$\Sigma$ & $\mathrm{kg}_{\text {water }} \mathrm{kg}_{\text {soil }}-1$ & Potential & Skin water at the surface of primary peds \\
\hline $\mathrm{T}_{1 / 2}$ & Min & Swelling & Time to half charge during swelling \\
\hline
\end{tabular}


a) The shrinkage curve or the specific volume of the pedostructure as a function of its water content, $\mathrm{V}(\mathrm{W})$

b) The swelling curve of the pedostructure specific volume as a function of time $\mathrm{V}(\mathrm{t})$ during wetting of a dry soil sample put in contact with water

c) The tensiometric curve or the interped water potential as a function of interped water content $h_{m a}\left(W_{m a}\right)$

d) The conductivity curve or the interped conductivity as a function of the interped water content $K_{m a}\left(W_{m a}\right)$.

\section{The shrinkage curve $\left(\mathrm{S}_{\mathrm{h}} \mathrm{C}\right)$}

This curve represents the soil fabric specific volume (V) in terms of its gravimetric moisture content $(\mathrm{W})$ which results from a standardized experiment where an unconfined and initially water saturated soil core sample is drying at a constant temperature. Under these experimental conditions, the $\mathrm{S}_{\mathrm{h}} \mathrm{C}$ can be assumed to represent the solid-water-air equilibrium configurations (under atmospheric pressure) and thus, define quantitatively the functional organization of the soil fabric. Consequently, the specific organizational variables, such as specific volumes, pore-volumes, water and air contents, of primary peds and of their assembly in the pedostructure are represented, at equilibrium, by a point ( $\mathrm{W}^{\mathrm{eq}}$, $\mathrm{V}^{\mathrm{eq}}$ ) of the $\mathrm{S}_{\mathrm{h}} \mathrm{C}$.

These organizational variables at equilibrium are entirely calculated from the $\mathrm{S}_{\mathrm{h}} \mathrm{C}$ characteristic parameters (Table 1), depending on only one of the two variables $\mathrm{V}^{\mathrm{eq}}$ or $\mathrm{W}^{\mathrm{eq}}$ since the parametric equation of the $\mathrm{S}_{\mathrm{h}} \mathrm{C}$ is known. [8], showed a sample of measured pedostructure moisture characteristic curves (water potential and soil shrinkage curves) as presented in Figure 2. They stated that the link between both curves is extended using the physical equation describing the soil water potential curve given by [11] as described in eq. 1. [8], explained that this equation relates the soil water pressure, $h_{m a^{\prime}}$ read on the tensiometer and the macro pore water content, $W_{m a}$ *

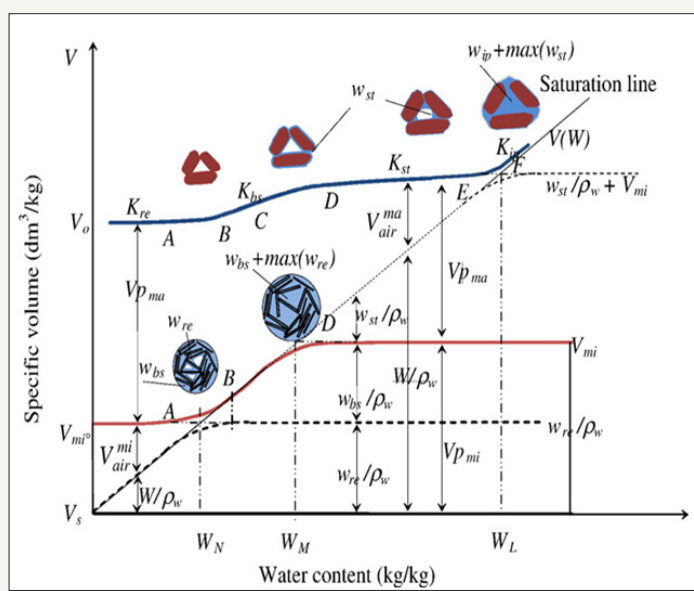

Figure 2: A graphical representation of the shrinkage curve

(1)

where $W_{m a}$ and $h_{m a}$ are the water content and the water potential in the macropores of the pedostructure (represented by the soil sample); $\rho_{w}$ is the water bulk density; $E_{m a}$ is the potential energy of the solid phase resulting from the external surface charge of the primary peds, in joules $/ \mathbf{k g}_{\text {soil }}$; $\sigma$ is a part of the micro-pore water at the surface of the primary peds, in $\mathrm{kg}_{\text {water }} / \mathrm{kg}_{\text {solids }}$; and $W_{\text {masat }}$ is the macro pore water content at saturation (corresponding to $h_{m a}=0$ ). $E_{m a^{\prime}} W_{\text {masat }}$ and $\sigma$ are the parameters of the potential curve.

\section{The swelling curve $\left(\mathrm{S}_{\mathrm{w}} \mathrm{C}\right)$}

This is the increase of the specific volume of a soil fabric sample with time, $V(t)$, when the dry aggregated sample is gently immersed in water [4]. They explained that the measurement of the $\mathrm{S}_{w} \mathrm{C}$ provides the unique parameter of the swelling equation, which is the coefficient of time characteristic of the clay plasma of primary peds. They used the swelling property of the aggregated soil fabric to represent the dynamics for the soil fabric (or pedostructure) to reach the equilibrium configurations expressed by the $S_{h} C$.

\section{Tensiometric and conductivity curves}

Mohtar RH [4] explained that the tensiometric and conductivity curves are the parametric variables of Darcy's law extended to the unsaturated soil medium that is described by the pedostructure model. According to [12] the tensiometric curve is dependent on the macropore water content. Mohtar RH [4], noted that the ShC allows for distinguishing directly and precisely a macropore space where water flows with no or weak structural volume change from this pore space, and a micro pore space (primary peds) where the movement of water is entirely related to the swelling pressure, $\mathrm{P}_{\text {smi' }}$ within the primary peds.

\section{Conclusion}

In geometric terms, it is difficult to quantify and characterize soil structure due to the complex formations and irregular patterns of the mass of individual particles, their inherently unstable nature and non-uniformity in space as influenced by certain external factors such as climate change, biological activities, farm operations etc. The pedostructure concept which models soil hydro-structural properties by exploring several properties of 
its internal organization could provide good quality information on soil structure, the aggregated organization and the hydrostructural dynamics. This could enhance the understanding of soil hydrological properties and the dynamics of soil processes, thus enabling soil structure characterization for efficient soil use and effective soil management for sustainable crop production.

\section{References}

1. Gregorich EG, Turchenek LW, Carter MR, Angers DA (2002) Soil and environmental Science Dictionary. CRC Press, Boca Raton, USA.

2. Hillel D (2003) Environmental Soil Physics. Elsevier Academic Press, Amsterdam, Netherlands, Europe, pp: 484.

3. Oshunsanya SO (2011) Soil Physics. Dabank Publishers, (1 $1^{\text {st }}$ edn), Nigeria, pp: 166.

4. Mohtar RH, Braudeau E (2006) Modelling soil water movement in pedostructure. Water Management and Soil Conservation in Semi-Arid Environments, The $14^{\text {th }}$ International Soil Conservation Organization Conference (ISCO 2006), Marrakech, Morocco, North Africa, pp: 6.

5. Braudeau E, Frangi JP, Mohtar RH (2004) Characterizing non-rigid dual porosity structured soil medium using its shrinkage curve. Soil Science Society of America Journal 68: 359-370.

6. Braudeau E, Mohtar RH, El Ghezal N, Crayol M, Salahat M, et al. (2009)
A multi-scale "soil water structure" model based on the pedostructure concept. Hydrology and Earth System Sciences Discussions 6(1): 11111163.

7. Braudeau E, Mohtar RH (2004) Soil water functions in pedostructure. In: Stewart BA, Howell T (Eds.), Encyclopaedia of Water Science. Marcel Dekker, New York, USA, p: 7.

8. Salahat M, Mohtar RH, Braudeau E, Schulze DG, Assi Amjad (2012) Toward delineating hydro-functional soil mapping units using the pedostructure concept: A case study. Computer and Electronics in Agriculture 86: 15-25.

9. Mallory JJ, Mohtar RH, Heathman GC, Schulze DG, Braudeau E (2011) Evaluating the effect of tillage on soil structural properties using the pedostructure concept. Geoderma 163(3-4): 141-149.

10. Timlin DJ, Ahuja LR, Pachepsky YA, Williams RD (1999) Use of BrooksCorey parameters to improve estimates of saturated conductivity from effective porosity. Soil Science Society of America Journal 63(5): 10861092.

11. Braudeau E, Mohtar RH (2006) Modelling the swelling curve for packed soil aggregates using the pedostructure concept. Soil Science Society of America Journal 70(2): 494-502.

12. Braudeau E, Mohtar RH (2004) Water potential in non-rigid unsaturated soil-water medium. Water Resources Research 40(5).
Creative Commons Attribution 4.0

International License

For possible submissions Click Here

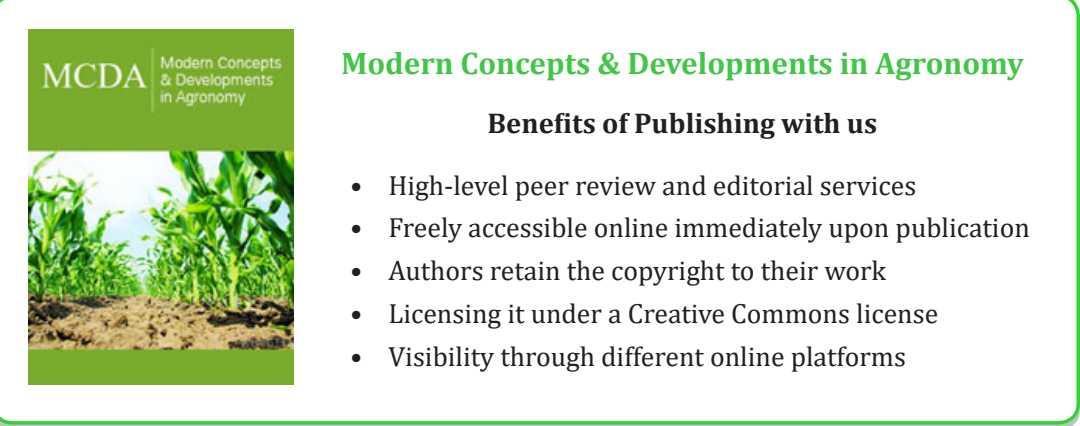

